\title{
Evaluation and Management of Vaginitis
}

\author{
Phyllis L. Carr, MD, Donna Felsenstein, MD, Robert H. Friedman, MD
}

\begin{abstract}
OBJECTIVE: To evaluate recent advances in our understanding of the clinical relevance, diagnosis, and treatment of vaginal infections, and to determine an efficient and effective method of evaluating this clinical problem in the outpatient setting.
\end{abstract}

DATA SOURCES: Relevant papers on vaginitis limited to the English language obtained through a MEDLINE search for the years 1985 to 1997 were reviewed.

DATA SYNTHESIS: Techniques that enable the identification of the various strains of candida have helped lead to a better understanding of the mechanisms of recurrent candida infection. From this information a rationale for the treatment of recurrent disease can be developed. Bacterial vaginosis has been associated with complications, including upper genital tract infection, preterm delivery, and wound infection. Women undergoing pelvic surgery, procedures in pregnancy, or pregnant women at risk of preterm delivery should be evaluated for bacterial vaginosis to decrease the rate of complications associated with this condition. New, more standardized criteria for the diagnosis of bacterial vaginosis may improve diagnostic consistency among clinicians and comparability of study results. Use of topical therapies in the treatment of bacterial vaginosis are effective and associated with fewer side effects than systemic medication. Trichomonas vaginalis, although decreasing in incidence, has been associated with upper genital tract infection. Therapy of $T$. vaginalis infection has been complicated by an increasing incidence of resistance to metronidazole.

CONCLUSIONS: Vaginitis is a common medical problem in women that is associated with significant morbidity and previously unrecognized complications. Research in recent years has improved diagnostic tools as well as treatment modalities for all forms of vaginitis.

KEY WORDS: vaginitis; diagnosis; therapy; yeast vaginitis; bacterial vaginosis; trichomonas vaginitis. J GEN INTERN MED 1998;13:335-346.

Received from the General Internal Medicine Unit (PLC) and Infectious Disease Unit (DF), Massachusetts General Hospital, and Section of General Internal Medicine, Boston University School of Medicine (RHF), Boston, Mass.

Address correspondence and reprint requests to Dr. Carr: Women's Health Associates, Blake 10, Massachusetts General Hospital, 32 Fruit St., Boston, MA 02114.
V aginitis is a common medical problem in women that is associated with substantial discomfort and frequent medical visits. Roughly 5 to 10 million office visits per year are attributed to vaginitis. ${ }^{1}$ Research in recent years has increased our understanding of the disease process and its potential sequelae and resulted in improved diagnostic and treatment modalities. ${ }^{2-6}$ Nevertheless, adequate diagnosis and treatment of vaginitis in the office setting often is problematic for practitioners. ${ }^{2,5,7-9}$ Moreover, the availability of over-the-counter medications for fungal vaginitis has increased the likelihood that women will come to medical attention with partially or inadequately treated infections. ${ }^{10}$ We will focus on the common infectious causes of vaginal discharge-yeast infection, bacterial vaginosis, and trichomonas infection, emphasizing new developments in diagnosis, associated complications, and treatment of these infections.

The initial evaluation of vaginal discharge requires an understanding of physiologic vaginal discharge and what differentiates it from abnormal, pathologic discharge. Substances from the vulvar, sebaceous, sweat, Bartholin's and Skene's glands, as well as exfoliated cells, cervical mucus, and secretions of the endometrial cavity and fallopian tubes constitute the normal physiologic secretions of the vagina. These secretions pool in the posterior fornix and do not adhere to the vaginal walls. ${ }^{11}$ The $\mathrm{pH}$ of normal vaginal secretions in women of childbearing age is between 3.8 and 4.5. The presence of sperm, blood, amniotic fluid, or cervical mucus raises the vaginal $\mathrm{pH} .{ }^{11}$ The amount and fluidity of the discharge can vary over the menstrual cycle. Cervical mucus becomes more fluid around ovulation, and women frequently mistake this change in consistency for an abnormal discharge. Stress increases the rate of vaginal desquamation and thus the amount of discharge, which patients can also mistake for a pathologic discharge. ${ }^{12}$ Women generally do not have other symptoms if their discharge is physiologic.

In contrast, a pathologic discharge adheres to the vaginal walls and is often accompanied by irritation, pruritus, odor, or urinary symptoms such as dysuria or frequency. ${ }^{6}$ The discharge can be thick to watery and frothy, and white to yellow, gray, or green. ${ }^{11}$ Causes of an abnormal discharge include infectious causes of vaginitis such as yeast infection, bacterial vaginosis, and trichomonas infection, as well as cervicitis and sexually transmitted diseases such as gonorrhea and chlamydia infection. Noninfectious etiologies include chemical irritants such 
as douching, perfumed toilet paper and deodorants, as well as the presence of a foreign body such as a tampon.

Atrophic vaginitis must also be considered in the differential of vaginal discharge. Women can present with a dry sensation or watery discharge with occasional spotting or bleeding. On examination, the vaginal mucosa is thinned, smooth, and light pink to white in appearance. ${ }^{8}$ A Pap smear with a maturation index can be helpful in diagnosing atrophic vaginitis if the results of clinical examination are equivocal. A therapeutic trial of topical estrogen can be helpful diagnostically. If symptoms of undiagnosed bleeding or irritation persist in a postmenopausal woman, referral to a gynecologist for vaginal or vulval biopsy should be considered after excluding infection and atrophic vaginitis. Atrophic vaginitis also occurs in women who are postpartum, or who are lactating, and in women with athletic amenorrhea. Medications causing similar symptoms include leuprolide, nafrelin, tamoxifen, danazol, some low-dose oral contraceptives, and contraceptives containing progesterone only such as Depo-provera and Norplant. ${ }^{13}$

A thoughtful approach to the patient with an abnormal vaginal discharge is necessary to determine the precise etiology and arrive at appropriate therapy. The most common etiologies of a pathologic discharge are the three infectious causes of vaginitis (yeast infection, bacterial vaginosis, and trichomonas infection), which we will review in detail.

\section{YEAST VAGINITIS}

\section{Pathology}

Candidal vulvovaginitis is a common clinical problem that affects most adult women at least once during their lifetime. ${ }^{14}$ Roughly $80 \%$ of yeast infections are due to Candida albicans with other Candida species including Candida glabrata and Candida tropicalis causing the remaining infections. ${ }^{14}$ However, $15 \%$ to $20 \%$ of women have asymptomatic colonization. ${ }^{2,15}$ The strain types are similar in symptomatic and asymptomatic women. ${ }^{14}$ Filamentous forms of yeast appear more likely to be associated with mucosal invasion, but both filamentous and budding forms of yeast are found in vaginal infections. ${ }^{16}$

Factors that contribute to the virulence of candida organisms are not well understood. Candida albicans has greater adherence to vaginal epithelial cells than C. tropicalis, and this may explain why more clinical infection is seen with this organism. Germinating cells that are more virulent also have greater adherence to epithelial cells. ${ }^{17}$ Although the symptoms of vaginal yeast infection are not strictly related to the number of organisms, the majority of women with symptomatic yeast infection have large numbers of yeast present, as well as evidence of germination. ${ }^{14}$

A number of factors increase susceptibility to vaginal yeast infection. Women who are pregnant or taking oral contraceptives have higher rates of yeast vaginitis. Estrogens have been shown to enhance the ability of candida to adhere to vaginal epithelial cells, thus promoting infection. ${ }^{18}$ Candida strains have also been shown to have a receptor for female reproductive hormones, which may facilitate yeast mycelial formation and virulence. ${ }^{14,19,20}$ Broad-spectrum antibiotics, particularly ampicillin, the tetracyclines, clindamycin, and the cephalosporins, facilitate vaginal yeast infections by eradicating normal vaginal flora. Normal flora inhibit yeast proliferation and germination through the elaboration of bacteriocins. ${ }^{21}$ Certain strains of lactobacilli have been shown to prevent colonization of vaginal cells with yeast in vitro by producing a protein that allows attachment of lactobacilli to the mucosal cell instead of yeast, thus decreasing the likelihood of infection. ${ }^{21}$ Other major contributors to vaginal yeast infection include diabetes and glycosuria, systemic steroids, obesity, and immunocompromise, including HIV infection. ${ }^{22}$ Recurrent yeast vaginitis can be a marker for immune deficiency. Any woman with frequent or difficultto-treat fungal vaginitis must be considered for HIV testing. Recurrent candidal vaginitis has been recognized as a complication of HIV infection, frequently occurring before other AIDS-defining diagnoses. ${ }^{23,24}$

Many women have frequently recurring yeast infections who do not have any of these common predisposing factors. ${ }^{14}$ Forty percent to $70 \%$ of recurrent candidal vaginitis can be attributed to an acquired candida-antigen specific cutaneous anergy. Reduced T lymphocyte reactivity to candida antigen permits candida proliferation and germination. ${ }^{25}$ Much of recurrent vaginal yeast infection is likely to be relapse rather than reinfection. ${ }^{26}$ Although vaginal cultures at the completion of therapy are generally negative, repeated cultures at 30 days have been found to be positive $25 \%$ to $30 \%$ of the time, with candida strains identical to those identified in the preliminary culture. ${ }^{27,28}$ Failure to eliminate all yeast from the vagina could permit small numbers of yeast to remain and later reestablish infection. More recent trends toward shorter treatment courses may inadequately eradicate the organism and result in higher rates of recurrent infection. ${ }^{25}$

Symptoms of recurrent candidal vaginitis can be due to a hypersensitivity reaction rather than invasive infection. This hypersensitivity reaction is often associated with increased vaginal secretions. ${ }^{16}$ The vaginal washes of $18 \%$ to $20 \%$ of patients with recurrent vaginitis reveal anti-candida IgE, suggesting an immediate hypersensitivity response. ${ }^{29,30}$ A coitus-related recurrent vaginitis has also been described that results from an allergic reaction to components of the partner's semen. The use of condoms has been reported to eliminate this form of recurrent vaginitis. ${ }^{31}$

A stress-induced yeast vaginitis is frequently described in women, as well as the development of yeast vaginitis immediately before menstruation. Although theories have been proposed to explain these clinical occurrences, ${ }^{3,32}$ the precise etiology of stress-induced and pre- 
menstrual yeast infections is unknown. During the past decade, it has been postulated that there has been a shift in the species of yeast that cause infection. Increases in C. glabrata and C. tropicalis, from roughly $10 \%$ of infections in the 1970 s to $20 \%$ in the 1980 s, have been reported. $^{33}$ Shortened courses of therapy may select for strains that are not as sensitive to the imidazoles, including C. glabrata and C. tropicalis. ${ }^{10,33}$ Other studies, however, have not borne this out, ${ }^{27}$ and this is probably not a major factor in recurrent yeast infection.

Asymptomatic penile yeast carriage of identical strains of candida occurs in $5 \%$ to $25 \%$ of male partners of symptomatic women with vaginal candidiasis. ${ }^{17,34-36}$ However, treatment of male sexual partners has not been shown to prevent recurrence in women, ${ }^{16}$ and yeast vaginitis occurs in women who are not sexually active. Sexual transmission is not a significant contributor to recurrent yeast vaginitis. $^{25}$

Vaginal reinfection has also been attributed to a persistent intestinal reservoir of candida. ${ }^{15}$ Identical strains from vaginal and rectal cultures have been found simultaneously in some studies. ${ }^{27,37}$ Long-term oral nystatin therapy to eradicate a gastrointestinal source of infection, however, has not been shown to decrease vaginal reinfection, ${ }^{38,39}$ and this most likely accounts for a small percentage of recurrent yeast vaginitis. ${ }^{25}$ Dietary factors have been postulated as a cause of recurrent yeast vaginitis. ${ }^{40}$ However, there is no conclusive evidence that diet plays a role in recurrent vaginal yeast infection. ${ }^{16}$ Yeast vaginitis is generally not associated with medical complications; however, abnormal Pap tests, usually mild squamous atypia, have been associated with this infection. ${ }^{41}$

\section{Clinical Presentation}

Women with yeast vaginitis frequently have prominent pruritus or irritation that can affect both the vagina and the vulvar area. ${ }^{42}$ Women may also experience urinary tract symptoms including frequency and dysuria in the absence of urinary infection or urethritis. ${ }^{6}$ On examination, the vaginal rugations are erythematous and inflamed with adherent vaginal discharge. The vulvar area, when infected, is erythematous with prominent scaling and, at times, fissures. When fissures are present, herpes simplex virus should be considered, and viral cultures should be obtained. Intertriginous areas of the groin can also be affected. The discharge of yeast vaginitis is thick and white to yellow and has been described as a "cottage cheese" discharge. ${ }^{11}$ Unlike the discharge of trichomonas infection or bacterial vaginosis, an absence of odor is characteristic of yeast vaginitis.

\section{Diagnosis}

The history can provide useful hints to the diagnosis of yeast vaginitis, such as exposure to broad-spectrum antibiotics, systemic steroids, or oral contraceptives. Although the newer low-dose estrogen oral contraceptives are not as frequently associated with yeast vaginitis, ${ }^{14}$ for some women they may increase the risk of infection, particularly if they have had a proclivity to yeast infections. Discontinuing oral contraceptives for these women can be helpful. On physical examination (Table 1), involvement of the vulvar area or the presence of fissures are highly suggestive of yeast vaginitis. ${ }^{2}$ Inflamed, erythematous vaginal rugations are usually present as well as a thick, adherent, white to yellow discharge.

The diagnosis of candidal vaginitis is made from observing hyphae on the potassium hydroxide wet mount preparation (Fig. 1). A large amount of discharge should be used to prepare the wet mount slide, as this facilitates the finding of hyphae. ${ }^{2}$ Hyphae on wet mount are highly predictive of yeast infection. ${ }^{2}$ Other clues that can point to a diagnosis of yeast are a pH less than 4.5 and a lack of odor to the discharge. The use of a vaginal culture is not recommended. It can be helpful, however, if the potassium hydroxide wet mount does not reveal hyphae, as occurs in $30 \%$ to $50 \%$ of cases. ${ }^{7}$ If a patient has used over-the-counter antifungal medication, she should dis-

Table 1. Diagnosis of Vaginal Infection

\begin{tabular}{|c|c|c|c|c|c|c|}
\hline Infection & Symptoms & $\begin{array}{l}\text { Physical } \\
\text { Examination }\end{array}$ & Discharge & Odor & $\mathrm{pH}$ & Diagnosis \\
\hline Yeast infection & Pruritus & $\begin{array}{l}\text { Fissures, } \\
\text { labial rash }\end{array}$ & $\begin{array}{l}\text { Thick, white to yellow, } \\
\text { "cottage cheese" }\end{array}$ & Absent & $<4.5$ & $\begin{array}{l}\mathrm{KOH} \text { wet prep + hyphae* } \\
{\mathrm{C} \& \mathrm{~S}^{\dagger}}^{*}\end{array}$ \\
\hline Bacterial vaginosis & $\begin{array}{l}\text { Variable, } 50 \% \\
\text { asymptomatic }\end{array}$ & & $\begin{array}{l}\text { Thin, white to gray, } \\
\text { homogeneous }\end{array}$ & $\begin{array}{l}\text { Present } \\
\text { (fishy) }\end{array}$ & $>4.5$ & $\begin{array}{l}\text { Clinical criteria, } 3 \text { of } 4^{\ddagger} \\
\text { Gram stain }\end{array}$ \\
\hline Trichomonas infection & $\begin{array}{l}\text { Pruritus, often } \\
\text { asymptomatic }\end{array}$ & $\begin{array}{l}\text { Strawberry } \\
\text { cervix }\end{array}$ & Profuse, green, watery & $\begin{array}{l}\text { Present or } \\
\text { Absent }\end{array}$ & $>4.5$ & $\begin{array}{l}\text { NS wet prep }+ \text { trichomonads }^{\S} \\
\mathrm{C} \& \mathrm{~S}^{\dagger}\end{array}$ \\
\hline
\end{tabular}

${ }^{*} \mathrm{KOH}$ wet prep is potassium hydroxide wet mount preparation.

${ }^{\dagger}$ C\&S (Culture and sensitivity) - to be used only if the diagnosis is not evident from the wet mount preparations.

${ }^{\ddagger}$ Clinical criteria: (1) thin, homogeneous discharge; (2) $p H>4.5$; (3) fishy odor with $\mathrm{KOH}$; and (4) clue cells.

$\S_{N S}$ wet prep is normal saline wet mount preparation. 


\section{ALGORITHIM FOR EVALUATION OF VAGINAL DISCHARGE}

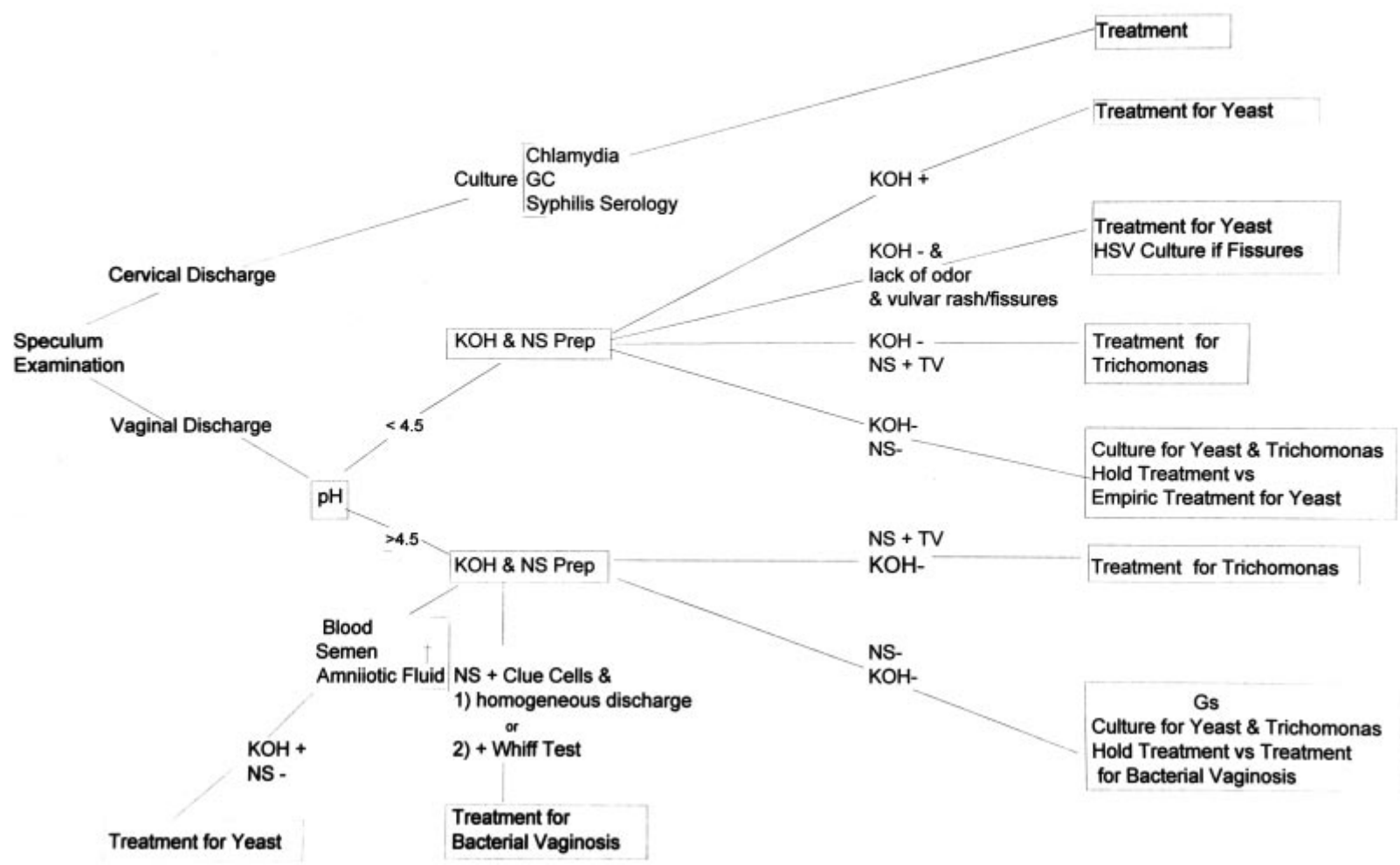

FIGURE 1. Suggested workup for patients with vaginitis. Tests and therapy are discussed in the text. $\mathrm{KOH}+$ indicates Hyphae observed on potassium hydroxide wet mount; NS+TV, Trichomonas observed on normal saline (NS) wet mount; NS+Clue, clue cells observed on normal saline (NS) wet mount; + Whiff Test, amine (fishy) odor when potassium hydroxide (KOH) is added to the discharge; HSV, herpes simplex virus; GS, gram stain; + Blood, semen, amniotic fluid causing spurious elevation of vaginal pH to $>4.5$.

continue use 3 days before a clinical examination, to improve the likelihood of a diagnosis at the time of the visit.

\section{Treatment}

For women with infrequent yeast vaginitis, over-thecounter preparations of miconazole and clotrimazole for 7 days are appropriate treatments and should be used as first-line therapy (Table 2). For patients with more of a vaginitis than a vulvitis, the suppositories may be more acceptable and have a higher cure rate than the creams, which are more effective in patients with vulvar involvement. ${ }^{43}$ If both vulvar and vaginal involvement are present, a combination of suppositories and cream is appropriate. In pregnancy, miconazole nitrate is recommended because of its limited absorption from mucous membranes. ${ }^{11}$ Miconazole is also available in a 3-day prescription-strength regimen. The shorter treatment courses, although likely to maximize patient compliance, are associated with a higher rate of recurrence. Other topical treatments have been used. Boric acid vaginal suppositories are effective when used twice a day for 2 weeks and can be considered if there is a contraindication to other treatments. ${ }^{44}$ Gentian violet has also been used, but many patients find it unacceptable, and there is a considerable rate of severe allergic reactions. ${ }^{11}$

Prescription medications should be reserved for women with frequently recurring vaginitis who have failed to improve with over-the-counter medication or for patients with compliance issues for whom shorter, higherdose treatment schedules may improve outcome. Terconazole $0.4 \%$ cream or $80-\mathrm{mg}$ suppositories nightly for 7 days, or $0.8 \%$ cream nightly for 3 days may be used. In some studies terconazole has a higher cure rate than over-the-counter medications, perhaps because of its effectiveness against C. glabrata. ${ }^{10,43}$ However, other studies have not borne this out. ${ }^{27}$

Newer 1-day oral regimens for yeast vaginitis are also available including fluconazole $150 \mathrm{mg}$ or itraconazole $200 \mathrm{mg}$. They are as effective as intravaginal treatment of vulvovaginal candidiasis, but gastrointestinal toxicity resulting in nausea, vomiting, and diarrhea is common, occurring in up to $15 \%$ of patients. ${ }^{45,46}$ One-dose topical treatments are also available (tioconazole 6.5\% vaginal ointment, clotrimazole 500-mg vaginal suppository), but appear to have less efficacy than other preparations. ${ }^{47}$

For patients with frequently recurrent candidal vaginitis, it is important to consider factors that predispose to infection. The discontinuation of oral contraceptives de- 
Table 2. Treatment Options for Vaginal Infections

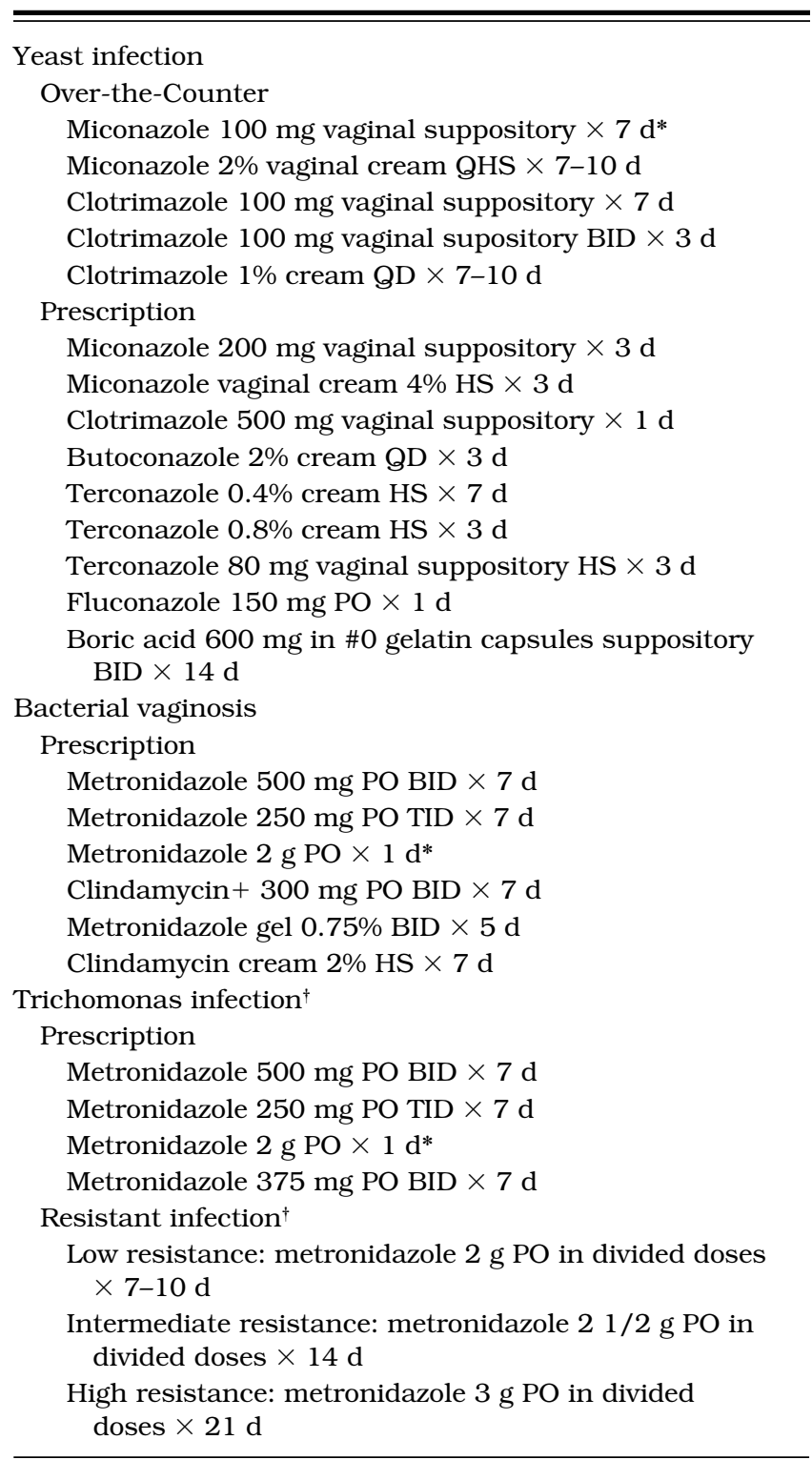

* Recommended treatment in pregnancy.

${ }^{\dagger}$ Treat the sexual partner as well.

${ }^{\ddagger}$ Resistant infection documented by recurrence and culture-determined resistance as low, intermediate, or high.

creases the frequency of yeast vaginitis for many women. ${ }^{11}$ Eliminating nylon and tight-fitting garments can also be helpful. ${ }^{48}$ Many diabetic patients with poor glycemic control have recurring yeast vaginitis; however, the routine use of oral glucose tolerance tests or glycosylated hemoglobin levels is not advocated unless there is further clinical evidence of diabetes. ${ }^{49}$ Patients with recurrent yeast vaginitis should, however, be tested for HIV. In one small study, the daily intake of $8 \mathrm{oz}$ of yogurt containing live Lactobacillus acidophilus has been shown to decrease candida colonization and vaginitis. ${ }^{50,51}$ Further study is required to determine if this is actually helpful in the management of recurrent yeast vaginitis. Hyposensitiza- tion with candida antigen has been reported to be effective for women who have an allergic vaginitis due to candida. ${ }^{52}$

When conventional treatment measures are ineffective, longer candicide treatment regimens are necessary, usually for 10 days to 2 weeks. For women with recurrent infection associated with menstruation, an intravaginal candicide such as clotrimazole vaginal suppositories, 100 mg nightly for several days prior to menstruation, may be effective. ${ }^{11}$ Alternatively, ketoconazole, $200 \mathrm{mg}$ orally twice a day for 5 to 7 days each month beginning prior to menstruation has been shown to be effective but is associated with a small risk of hepatotoxicity. A regimen of ketoconazole, $100 \mathrm{mg}$ daily for 6 months, has only a $5 \%$ recurrence rate for yeast infection. ${ }^{53}$ This low dose is felt to inhibit germination of yeast. ${ }^{25}$ In addition to hepatotoxicity, ketoconazole has significant drug interactions with other frequently used medications. Fluconazole, $150 \mathrm{mg}$ once a week or monthly, has less hepatic toxicity and is a reasonable alternative. The risks of suppressive therapy should be weighed against the potential benefits, including the potential for the development of resistant strains of yeast. Monthly use of an over-the-counter candicide prior to menstruation is preferable to long-term suppressive therapy for most patients.

\section{BACTERIAL VAGINOSIS}

\section{Pathology}

Bacterial vaginosis has a complex and poorly understood pathophysiology, ${ }^{54}$ even though it is a frequent cause of vaginitis in women. ${ }^{33}$ The prevalence of this disorder is underestimated, as 50\% of women with bacterial vaginosis are asymptomatic. ${ }^{55}$ The nomenclature for this infection has changed in recent years, from nonspecific vaginitis to bacterial vaginosis-the term "vaginosis" reflecting the lack of an inflammatory component. Symptoms of bacterial vaginosis result from overgrowth of certain bacterial species, concurrent with a decrease in normal flora and lactobacilli. In addition, strains of lactobacilli that produce hydrogen peroxide are often replaced by nonproducing strains. ${ }^{55}$ Ninety-six percent of normal women have hydrogen peroxide-producing Lactobacillus species compared with only $6 \%$ of women with bacterial vaginosis. ${ }^{56}$ The production of hydrogen peroxide by lactobacilli combines with chlorine, a halide present in cervical mucus, to produce a nonspecific antimicrobial host defense. The combination of these substances is toxic to some of the organisms associated with bacterial vaginosis, including Gardnerella vaginalis and prevotella. The level of hydrogen peroxide available to combine with chlorine in the vagina may influence susceptibility to bacterial vaginosis. ${ }^{56}$

A number of organisms are associated with this infection including G. vaginalis, Myocoplasma hominis, Mobiluncus species, Bacteroides species other than B. fragilis, and other anaerobic gram-positive cocci such as prevo- 
tella and Peptostreptococcus. ${ }^{57}$ The exact mechanism by which these organisms cause infection is not established. ${ }^{2}$ Gardnerella vaginalis is present in many women without symptoms of vaginal infection. Carrier rates of this organism in some series are as high as $10 \%$ to $40 \%$ of normal women. ${ }^{22}$ The presence of this organism does not prove infection ${ }^{57-59}$; however, in women with bacterial vaginosis, the concentration of $G$. vaginalis is two to three logs higher than in normal women.

High rates of bacterial vaginosis have been reported from sexually transmitted disease clinics, but the role of sexual transmission of bacterial vaginosis is unclear. Many of the studies are small, and prevalence ranges are broad.4,60-62 Male sexual contacts of women with bacterial vaginosis have been shown to carry similar organisms. ${ }^{11}$ Evidence against sexual transmission, however, includes similar rates (approximately 15\%) of bacterial vaginosis in a population of prostitutes and a population of college students in Seattle. ${ }^{63,64}$ Moreover, treatment of sexual partners does not reduce the risk of recurrence. ${ }^{54}$ Bacterial vaginosis has also been found in virginal adolescents. ${ }^{65}$ Bacterial vaginosis is most likely associated with sexual transmission through the disruption of normal vaginal flora but is not a sexually transmitted disease.

The prevalence of bacterial vaginosis has varied with the method of contraception. The use of an intrauterine device has been associated with a higher rate of bacterial vaginosis compared with women using other means of contraception $(20 \%$ vs $6 \%) .{ }^{60,61}$ Women who do not use any form of contraception have also been found to have a higher rate of bacterial vaginosis. ${ }^{59,66}$ The reason for these variations with contraceptive use is not clear. There is twice the incidence of bacterial vaginosis in African-American women than white women. ${ }^{67}$ The higher vaginal $\mathrm{pH}$ found in African-American women ${ }^{68}$ may increase their susceptibility to bacterial vaginosis.

Bacterial vaginosis has been associated with a number of complications including an increased rate of abnormal Pap smears, usually atypical squamous cells of undetermined significance (ASCUS). ${ }^{69,70}$ Women with ASCUS should be evaluated for bacterial vaginosis as they are frequently concurrent problems. ${ }^{69,70}$ Bacterial vaginosis has also been associated with pelvic inflammatory disease (PID). ${ }^{71}$ Eschenbach found a higher rate of adnexal tenderness as well as a clinical diagnosis of PID in women with bacterial vaginosis than in those without bacterial vaginosis attending a sexually transmitted disease clinic. ${ }^{4}$ The microorganisms of bacterial vaginosis are commonly isolated from the upper genital tract of patients with acute salpingitis, and bacterial vaginosis is a frequent concurrent diagnosis in patients with PID. ${ }^{72}$ The association of bacterial vaginosis with PID is controversial, and other studies have disputed bacterial vaginosis as an etiology of PID. ${ }^{73}$ The finding of an increased incidence of plasma cell endometritis in women with bacterial vaginosis is supportive of an association between bacterial vaginosis and upper genital tract infection. The presence of plasma cells is a marker for endometritis or upper genital tract disease. Plasma cell endometritis in one study was distinctly associated with bacterial vaginosis, but not with gonorrhea or chlamydia infection. ${ }^{74}$

Premature rupture of membranes and preterm delivery of low-birth-weight infants has also been reported with bacterial vaginosis in several case-control and cohort studies. ${ }^{75-78}$ Up to a 7.3 -fold increased risk (95\% confidence interval $1.8,29.4$ ) for premature rupture of membranes in women with bacterial vaginosis has been found. ${ }^{79}$ Treatment of bacterial vaginosis with oral metronidazole in patients with prior preterm birth has been shown to reduce prematurity (18\% vs $39 \%$ ) and premature rupture of membranes (5\% vs $33 \%$ ). ${ }^{80}$ Furthermore, antibiotic treatment including tetracycline, erythromycin, and clindamycin has been shown to increase newborn weight among treated mother-infant pairs. ${ }^{81}$ This may reflect treatment of ureaplasma urealyticum rather than bacterial vaginosis. Bacteroides has been isolated from the vaginal cultures of women who have infants weighing less than 2,500 $\mathrm{g}$ and who are more likely to give birth before 37 weeks' gestation. ${ }^{82,83}$ Among women with bacterial vaginosis, the highest risk of preterm delivery of a lowbirth-weight infant was in women who had vaginal cultures positive for both Bacteroides and Mycoplasma hominis. ${ }^{84}$ In addition, treatment with metronidazole of asymptomatic pregnant women at risk of preterm delivery who have bacterial vaginosis in the second trimester reduces the incidence of preterm delivery. 85

Postpartum endometritis following cesarean section occurs at five times the rate in women with bacterial vaginosis as in women without this diagnosis. Organisms including G. vaginalis, facultative bacteria, and anaerobes recovered from the endometrial cavity of $60 \%$ of women with postpartum endometritis were associated with bacterial vaginosis. ${ }^{80,83,86}$ Postpartum wound infection after cesarean section may also occur more commonly in women with bacterial vaginosis. ${ }^{54}$ Because of these associated complications, accurate diagnosis of bacterial vaginosis is increasingly important in pregnancy and prior to pelvic surgery.

\section{Clinical Presentation}

Women with bacterial vaginosis have an extremely variable clinical presentation. The vaginal discharge is frequently the most noticeable symptom. Patients are particularly troubled by the fishy amine odor of the discharge, which is thin, homogeneous, and gray to white in color. ${ }^{11}$ Many patients have no symptoms. ${ }^{55}$ The clinical examination is marked by the lack of vulvar and groin involvement and normal-appearing vaginal rugations.

\section{Diagnosis}

The traditional diagnosis of bacterial vaginosis has been clinical, requiring three of four criteria in the evalua- 
tion of a vaginal discharge (Table 1). These criteria include (1) a pH of 4.5 or higher, (2) an amine or fishy odor with the addition of potassium hydroxide to the discharge (positive Whiff test), (3) a thin homogeneous discharge, and (4) the presence of clue cells on microscopy. ${ }^{57}$ A clue cell is a squamous epithelial cell whose border is obscured by adherent bacteria (Fig. 2). ${ }^{22}$ The presence of clue cells indicates greater numbers of organisms, including Gardnerella, which is thought to be indicative of infection. ${ }^{23}$ The normal saline wet mount should utilize a small amount of discharge with copious amounts of saline to disperse the epithelial cells and facilitate the finding of clue cells. ${ }^{2}$ The increase in vaginal $\mathrm{pH}$ and fishy odor that characterizes this discharge results from the proliferation of anaerobic bacteria and the resultant production of amines and vaginal organic acids. ${ }^{78}$ The addition of $10 \%$ potassium hydroxide intensifies the fishy odor when it is added to vaginal secretions by converting the amines to a more volatile state. ${ }^{2}$ The use of gas-liquid chromatography of vaginal secretions to diagnose bacterial vaginosis is also based on this phenomenon. ${ }^{86,87}$ The discharge usually contains very few white cells although the presence of greater numbers of white cells does not exclude the diagnosis. A pH less than 4.5, however, is not consistent with a clinical diagnosis of bacterial vaginosis. ${ }^{2,4}$

Interclinician variability in making the diagnosis of bacterial vaginosis and the association with upper reproductive tract complications makes accurate diagnosis of this condition more vital. $2,5,57$ This has spurred investigators to evaluate other methods of diagnosis for bacterial vaginosis. The gram stain appears to be better than gasliquid chromatography, the proline aminopeptidase test, or vaginal cultures in predicting infection. ${ }^{2,57}$ The Spiegel criteria base the diagnosis of bacterial vaginosis on the gram stain. The diagnosis requires the presence of fewer than five Lactobacillus morphotypes, five or more Gardnerella morphotypes, and five or more other morphotypes (gram-positive cocci, small gram-negative rods, curved

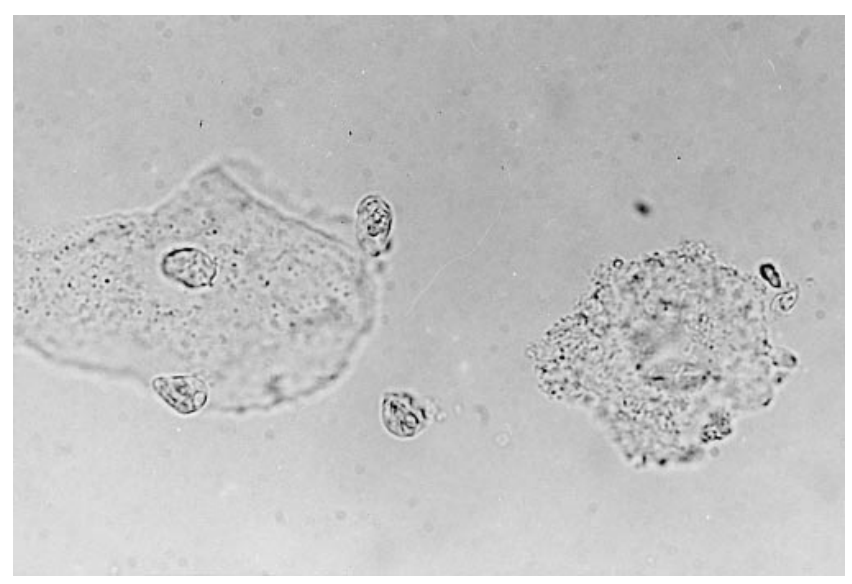

FIGURE 2. Epithelial cell and clue cell. 1000×. Normal saline wet preparation showing "clue cell" (R) with obvious granulation within the epithelial cell and obliteration of the cell border. gram-variable rods, or fusiforms) per high-power field. ${ }^{88}$ The Vaginal Infection and Prematurity Study Group developed a more widely utilized method to diagnose bacterial vaginosis using the gram stain, the Nugent system. ${ }^{5} \mathrm{~A}$ scoring system from 0 to 10 grades the severity of bacterial vaginosis using the most reliable bacterial morphotypes to create a summary score of the alteration in vaginal flora. A score of 0 to 3 represents normal flora, 4 to 6 is indeterminate, and 7 to 10 is diagnostic of bacterial vaginosis. ${ }^{5}$ The Nugent system has become the "gold standard" for diagnosing bacterial vaginosis.

The use of a vaginal culture to diagnose bacterial vaginosis is not advocated. However, in clinical practice a vaginal culture is frequently obtained from the patient with symptoms when a conclusive diagnosis cannot be obtained from the wet mount preparations during the office visit. A culture result of absent normal flora and abundant gardnerella can be helpful in pointing to a diagnosis of bacterial vaginosis in such patients. However, a vaginal smear is far more useful and cost-effective and should always be obtained before a vaginal culture is considered.

\section{Treatment}

Until recently, the standard treatment of symptomatic disease was metronidazole, $500 \mathrm{mg}$ orally twice a day or $250 \mathrm{mg}$ orally three times a day for 7 days, resulting in a cure rate of $80 \%$ to $90 \%$ (Table 2). ${ }^{55,63}$ Alternatively, a single oral 2 -g dose of metronidazole can be given, which results in lower rates of secondary yeast infection and equal initial cure rates of $80 \%$ to $90 \% .{ }^{89}$ The shorterduration regimen, however, may have a higher recurrence rate. ${ }^{55}$ For compliant patients, one of the longer treatment courses is preferable and has greater efficacy than the single-dose regimen.

The availability of topical preparations has obviated the need for systemic therapy in many patients. Metronidazole $0.75 \%$ vaginal gel twice a day for 5 days has the advantage of fewer systemic reactions. Other regimens include clindamycin $2 \%$ cream vaginally for 7 nights, ${ }^{90}$ and clindamycin $300 \mathrm{mg}$ orally twice a day for 7 days. Their efficacy appears to be high-93\% at 1 week, and $89 \%$ at 1 month. ${ }^{91,92}$ However, the oral form may result in a higher incidence of diarrhea and colitis. The topical preparations are only minimally absorbed, reaching $2 \%$ to $5 \%$ of the mean peak serum concentration of systemic therapy, resulting in much lower toxicity. Ampicillin and doxycycline are not as effective in treating bacterial vaginosis (cure rates $40 \%-60 \%$ ) and generally should not be used.63,93 Topical sulfonamide creams have been used for many years in the therapy of bacterial vaginosis, but there are no data to support their use. Two randomized, doubleblind trials have not shown a benefit from treating the sexual partner, ${ }^{94,95}$ and this is not recommended.

Among women treated with metronidazole, 20\% to $30 \%$ will have a recurrence in 3 months. ${ }^{52}$ Although met- 
ronidazole is highly active against anaerobic bacteria, it is less active against $G$. vaginalis and poor against Mobiluncus species. Despite this, a repeated 7-day course of metronidazole is often effective treatment for a recurrence. A small number of women will have multiple recurrences. Treatment for these patients is not established. However, prolonged oral metronidazole use is associated with a risk of peripheral neuropathy, ${ }^{55}$ and this must be considered in patients requiring repetitive therapy. Because of its very limited systemic absorption, this is unlikely to be a problem with topical metronidazole.

The treatment of bacterial vaginosis during pregnancy is metronidazole, $250 \mathrm{mg}$ orally three times a day for 7 days, or $2 \mathrm{~g}$ orally in a single dose. ${ }^{96}$ Lower doses are recommended to limit the exposure of the fetus to medication. The effect of metronidazole on the fetus during any stage of pregnancy has been a matter of concern. A 1995 meta-analysis of seven prospective studies and one retrospective study of first-trimester exposure to metronidazole found no increase in the risk of teratogenesis from such exposure. ${ }^{97}$ Clindamycin, $300 \mathrm{mg}$ orally twice a day for 7 days, can also be used in pregnancy. ${ }^{96,98}$ However, clindamycin vaginal cream is not recommended because of the finding of an increase in preterm birth in women treated with clindamycin cream. ${ }^{96,99}$ Topical treatments for bacterial vaginosis in pregnancy may not be adequately effective to reduce preterm delivery, and systemic therapy may be required. ${ }^{99}$

At present, routine treatment of asymptomatic disease is not recommended (Fig. 3). ${ }^{58,100}$ Previous studies have suggested a high spontaneous resolution of bacterial vaginosis. ${ }^{58}$ Despite concern of the risk of PID in untreated patients with bacterial vaginosis, most infections are uncomplicated. Thus, unless a vaginal surgical procedure is contemplated or the patient is pregnant, ${ }^{58,100}$ treatment of the asymptomatic patient is not indicated. Pregnant patients and those undergoing vaginal surgical procedures should be screened and appropriately treated prior to delivery or the vaginal surgical procedure. Recommendations may change as our understanding of this infection grows.

\section{TRICHOMONAS VAGINITIS}

\section{Pathology}

The incidence of trichomonas infection has been declining for the past 20 years, and currently this accounts for only $10 \%$ to $25 \%$ of vaginal infections, depending on the population studied. ${ }^{33,101,102}$ Sexually transmitted disease clinics report a higher incidence of this infection. Risk factors for trichomonas infection include lower socioeconomic status and having a greater number of sexual partners. Cigarette smoking as well as African-American race have also been linked to trichomonas infection, even after adjustment for income and level of education. In addition, women who stop smoking are no more likely to be infected than nonsmokers, suggesting that smoking in-

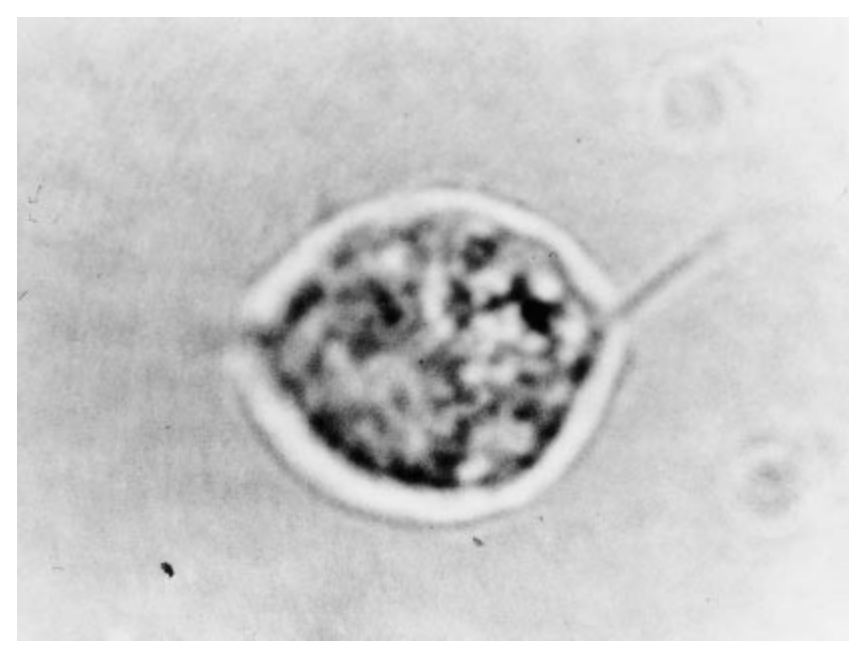

FIGURE 3. Trichomonas vaginalis. $1000 \times$. Organism with flagella seen on normal saline wet preparation.

creases trichomonas colonization through a physiologic effect on the vaginal environment. ${ }^{101}$ The organism has been found to coexist with a number of other infections, including gonococcal infection and bacterial vaginosis. ${ }^{11,103}$ Concurrent bacterial vaginosis and trichomoniasis were found in $22 \%$ of pregnant adolescents in one study. ${ }^{104}$ Trichomonads generate hydrogen, which combines with oxygen, removing oxygen from the vaginal ecosystem. ${ }^{105}$ This may facilitate growth of other anaerobic bacteria and predispose the person to bacterial vaginosis, although this has not been confirmed.

The organism, slightly larger than a leukocyte, is a motile protozoan with four flagella. Its vigorous mechanical motion is felt to be cytotoxic, and causes a variable amount of vaginal mucosal erythema. ${ }^{106}$ The characteristic "strawberry cervix," caused by intraepithelial hemorrhages, is seen in only $5 \%$ to $10 \%$ of patients. ${ }^{2,101}$ Virulence is highly variable among the different strains, and $25 \%$ to $50 \%$ of women who are culture positive for Trichomonas vaginalis are asymptomatic. Trichomonas vaginalis can be recovered from the urine in up to $30 \%$ of male sexual contacts of women with the infection; however, less than $20 \%$ of men with trichomonas in the urine are symptomatic. ${ }^{104}$ Trichomonas infection is a sexually transmitted disease. However, sexual infection may not be the sole mode of transmission. The organism has been shown to survive in hot tubs, tap water, and chlorinated swimming pools. These modes of spread are uncommon, but should be considered when recurrent infection is a problem. ${ }^{107}$

Trichomonas infection is also associated with complications, including abnormal Pap tests ${ }^{40}$ and PID. ${ }^{108} \mathrm{Ab}-$ normal Pap tests are more frequent, however, in patients with bacterial vaginosis. ${ }^{69}$ Trichomonas acts as a vector for the development of PID, with the motility of the organism facilitating movement of microorganisms from the vagina to the fallopian tubes. ${ }^{108}$ Premature rupture of mem- 
branes in pregnancy and neonatal respiratory tract infection have also been associated with this organism. ${ }^{78,109}$ It is difficult to determine the independent impact of $T$. vaginalis in adverse pregnancy outcomes because of the association of trichomonas infection with smoking and lower socioeconomic status. ${ }^{110}$

\section{Clinical Presentation}

Women with trichomonas vaginitis generally present with a malodorous, profuse, frothy, watery, green discharge. ${ }^{11}$ Pruritus is a more frequent symptom than in patients with bacterial vaginosis, but less common than in those with yeast vaginitis. Some patients report very little in the way of symptoms. ${ }^{105}$ The vulvar and intertriginous groin areas are spared, and the vaginal rugations are typically only mildly inflamed.

\section{Diagnosis}

Copious watery discharge is usually evident, which may be gray to green in color. The discharge has a normal to very alkaline $\mathrm{pH}$, usually 6 to 7 , and many white blood cells are often present. ${ }^{105}$ The normal saline wet mount, which reveals the organism $60 \%$ to $75 \%$ of the time, is the most cost-effective method of diagnosis. ${ }^{111}$ Although a Pap test can suggest trichomonas infection, the test produces significant numbers of false-positive and falsenegative results. Trichomonas infection found by Pap smear should be confirmed by wet mount or culture prior to treatment. ${ }^{3,40,111}$

The most sensitive diagnostic modality is a trichomonas culture, which is relatively inexpensive. ${ }^{111,112}$ Despite the low cost, many laboratories do not culture trichomonas. This requires a special liquid medium (Diamond's) that allows growth of the organism so that it can be subsequently visualized on wet mount. The In Pouch TV culture system has been found to perform as reliably as Diamond's medium in recovering $T$. vaginalis isolates and may be an alternative to traditional culture techniques. ${ }^{74}$ With the increasing incidence of metronidazole resistance, ${ }^{112}$ cultures may become more standard practice. ${ }^{2}$ Several other methods are also being evaluated for the diagnosis of trichomonas infection, including a polymerase chain reaction-based test, ${ }^{26,113}$ a direct fluorescent antibody test, and an enzyme immunoassay. ${ }^{110}$ Sensitivities and specificities of these tests, however, are not clearly established. ${ }^{108}$ Fluorescent antibody tests are commercially available; however, the sensitivity of these tests is low, and use of a fluorescent microscope is needed.

\section{Treatment}

Options for the treatment of trichomonas infection include metronidazole at $500 \mathrm{mg}$ orally twice a day for 7 days, $250 \mathrm{mg}$ orally three times a day for 7 days, or $2 \mathrm{~g}$ orally in a single dose. Any of these regimens results in a cure rate of $86 \%$ to $97 \%$ when the sexual partner is treated concurrently, as recommended by the Centers for Disease Control and Prevention. ${ }^{107,114-117}$ The FDA has approved a 375-mg dose orally twice a day for 7 days, as serum levels are similar to the 250-mg regimen three times a day. ${ }^{96}$ However, the single-dose regimen is preferable for maximizing patient compliance. Topical intravaginal metronidazole is not effective treatment for trichomonas infection, as adequate levels of medication are not achieved in the urethra or perivaginal glands. ${ }^{96}$

Recommendations for treatment in pregnancy are changing with the evident safety of metronidazole in pregnancy, ${ }^{97}$ and the association of trichomonas infection with adverse pregnancy outcomes. A regimen of $2 \mathrm{~g}$ of metronidazole in a single dose is the treatment of choice for trichomonas infection in women in all trimesters of pregnancy. ${ }^{96}$ Patients allergic to metronidazole should be desensitized. ${ }^{96}$ Clotrimazole, $100 \mathrm{mg}$ intravaginally at bedtime for 5 to 10 days, has been used for symptomatic relief, although this is not an FDA-approved indication for this medication. ${ }^{118}$ If invasive technologies such as chorionic villous sampling or cerclage placement are necessary in pregnancy, preprocedure prophylaxis in infected patients is indicated to avoid procedure-related infection and complications. ${ }^{105}$

Resistant trichomonas strains have been reported. Before assuming that an infection is resistant to metronidazole, it is important to ascertain the compliance of the patient and her partner. The concurrent use of medications such as phenobarbitol and phenytoin should be determined, as they can interfere with the action of metronidazole and decrease its effectiveness. When true resistance is present, it is generally a relative resistance, and higher doses of metronidazole, such as $750 \mathrm{mg}$ four times a day for 6 to 10 days or longer, usually result in a cure. ${ }^{110}$ Very highly resistant trichomonas infection has been reported, but this is rare ( 1 in 2,000 to 3,000 cases). ${ }^{110}$ A combination of vaginal metronidazole by suppository, $500 \mathrm{mg}$ a day for 5 days, concurrently with oral metronidazole therapy has been effective in these cases. ${ }^{105,110}$ Intravenous metronidazole regimens $(500 \mathrm{mg}$ every $6-8 \mathrm{~h}$ for $3 \mathrm{~d}$ ) have also been used for resistant cases. ${ }^{119}$ Daily doses greater than $3 \mathrm{~g}$ of metronidazole can cause neurologic injury, and this should be considered when choosing a regimen. Intravaginal nonoxynol-9 relieves symptoms of trichomonas vaginitis, but seldom results in cure. ${ }^{110,119}$ Tinidazole, available in Canada and Europe, can achieve cure in some cases, because crossresistance with metronidazole is incomplete. ${ }^{110}$

\section{SUMMARY}

Vaginitis is a common medical problem in women that can be associated with significant morbidity and complications. Strain typing of Candida permits a better understanding of recurrent yeast infection that can aid in its treatment. More standardized methods of diagnosis in 
bacterial vaginosis such as Nugent's criteria are important in further assessing potential complications associated with bacterial vaginosis including premature rupture of membranes, chorioamnionitis, preterm delivery, postpartum endometritis, wound infection, and PID. Patients who are pregnant and in need of an invasive procedure or any woman undergoing pelvic surgery should be screened and treated prior to the procedure. Topical treatments for bacterial vaginosis including clindamycin cream and metronidazole gel have decreased the need for systemic treatment, but should be used with caution in pregnant patients, and cure should be documented. Trichomonas infection is also associated with upper genital tract infection and an increasing incidence of metronidazole resistance, which should be considered in patients with recurrent infection. Research in recent years has provided improved diagnostic tools as well as treatment modalities for all forms of vaginitis.

\section{REFERENCES}

1. Paavonen J, Stamm WE. Lower genital tract infections in women. Infect Dis Clin North Am. 1987;1:179-98.

2. Eschenbach DA, Hillier SL. Advances in diagnostic testing for vaginitis and cervicitis, J Reprod Med. 1989;34:555-65.

3. Witkin SS. Imunologic factors influencing susceptibility to recurrent candidal vaginitis. Clin Obstet Gynecol. 1991;34:662-8.

4. Eschenbach DA, Hillier S, Critchlow C, et al. Diagnosis and clinical manifestation of bacterial vaginosis. Am J Obstet Gynecol. 1988;158:819-28.

5. Nugent RP, Krohn MA, Hillier SL. Reliability of diagnosing bacterial vaginosis is improved by a standardized method of gram stain interpretation. J Clin Microbiol. 1991;29:297-301.

6. Draper D, Parker R, Patterson E, et al. Detection of Trichomonas vaginalis in pregnant women with the In Pouch TV culture system. J Clin Microbiol. 1993;31(4):1016-8.

7. Schaaf VM, Perez-Stable EJ, Borchardt K. The limited value of symptoms and signs in the diagnosis of vaginal infections. Arch Intern Med. 1990;150:1929-33.

8. Berg AO, Heidrich FE, Fihn SD, et al. Establishing the cause of genitourinary symptoms in women in a family practice. JAMA. 1984;251:620-5.

9. Carr FL, Thabault P, Levenson S, Friedman RH. Vaginitis in a community based practice. Clin Res. 1992;40:554A. Abstract.

10. Horowitz BJ, Giaquinta D, Ito S. Evolving pathogens in vulvovaginal candidiasis: implications for patient care. J Clin Pharmacol. 1992;32:248-55.

11. Hill LVH, Embil JA. Vaginitis: current microbiologic and clinical concepts. Can Med Assoc J. 1986;134:321-31.

12. Friedrich EG. Vaginitis. Am J Obstet Gynececol. 1985;152:247-51.

13. Beard MK. Atrophic vaginitis: can it be prevented as well as treated? Postgrad Med. 1992;91:257-60.

14. Sobel JD. Epidemiology and pathogenesis of recurrent vulvovaginal candidiasis. Am J Obstet Gynecol. 1985;152:924-34.

15. Odds FC. Genital candidosis. Clin Exp Dermatol. 1982;7:345-54.

16. Sobel JD. Pathophysiology of vulvovaginal candidiasis. J Reprod Med. 1989;34(8 suppl):S572-80.

17. King RD, Lee JC, Morris AL. Adherence of Candida albicans and other Candida species to mucosal epithelial cells. Infect Immun. 1980;27:667-74.

18. Powell BL, Frey CL, Drutz L. Estrogen receptor in Candida albicans: a possible explanation for hormonal influences in vaginal candidiasis. Presented at the 23rd Interscience Conference on
Antimicrobial Agents and Chemotherapy, Las Vegas, Nev, October 24-26, 1983. Abstract 751.

19. Kinsman OS. Effect of mammalian steroid hormones and luteinizing hormone on germination of $C$. albicans. Presented at the American Society of Microbiology Conference on Candida albicans, Palm Springs, Calif, May 16,1987. Abstract 27.

20. Davidson F, Oates JK. The pill does not cause "thrush." Br J Obstet Gynaecol. 1985;92:1265-6.

21. McGroarty J, Moody K. In vitro inhibition of growth adhesion of Candida albicans by vaginal isolates of lactobacilli. Presented at the 33rd Interscience Conference on Antimicrobial Agents and Chemotherapy, New Orleans, La, October 1993.

22. Sweet RL. Importance of differential diagnosis in acute vaginitis. Am J Obstet Gynecol. 1985;152:921-3.

23. Rhoads JL, Wright C, Redfield RR, et al. Chronic vaginal candidiasis in women with human immunodeficiency virus infection. JAMA. 1987;253:3105-7.

24. 1993 Revised classification system for HIV infection and expanded surveillance case definition for AIDS among adolescents and adults. MMWR. 1992;15:245-9.

25. Sobel JD. Pathogenesis and treatment of recurrent vulvovaginal candidiasis. Clin Infect Dis. 1992;14(suppl 1):S148-53.

26. Sobel JD. Recurrent vulvovaginal candidosis. What we know and what we don't. Ann Intern Med. 1984;101:390-2.

27. O'Connor MI, Sobel JD. Epidemiology of recurrent vulvovaginal candidiasis: identification and strain differentiation of Candida albicans. J Infect Dis. 1986;154:358-63.

28. Odds FC. Candidosis of the genitalia. In: Odds FC, ed. Candida and Candidosis. 2nd ed. London, UK: Bailliere Tindall; 1988:124-35.

29. Rosedale N, Browne K. Hyposensitization in the management of recurring vaginal candidiasis. Ann Allergy. 1979;43:250-3.

30. Palacios HJ. Hypersensitivity as a cause of dermatologic and vaginal moniliasis resistant to topical therapy. Ann Allergy. 1976; 37:110-3.

31. Witkin SS, Yu IR, Ledger WJ. Inhibition of Candida albicansinduced lymphocyte proliferation by lymphocytes and sera from women with recurrent vaginitis. Am J Obstet Cynecol. 1983;147: 809-11.

32. Kalo-Klein A, Witkin SS. Candida albicans and cellular immune system interactions during different stages of the menstrual cycle. Am J Obstet Gynecol. 1989;161:1132-6.

33. Kent HL. Epidemiology of vaginitis. Am J Obstet Gynecol. 1991; 165:1168-76.

34. Rodin P, Kolator B. Carriage of yeasts on the penis. BMJ. 1976; $1: 1123-4$.

35. Thin RN, Leighton M, Dixon MJ. How often is genital yeast infection sexually transmitted? BMJ. 1977;2:93-4.

36. Davidson F. Yeasts and circumcision in the male. Br J Vener Dis. 1977;53:121-2.

37. Meinhof WL. Demonstration of typical features of individual Candida albicans strains as a means of studying sources of infection. Chemotherapy. 1982;28(suppl 1):51-5.

38. Milne JD, Warnock DW. Effect of simultaneous oral and vaginal treatment on the rate of cure and relapse in vaginal candidosis. Br J Vener Dis. 1979;55:362-6.

39. Vellupillai S, Thin RN. Treatment of vulvovaginal yeast infection with nystatin. Practitioner. 1977;219:897-901.

40. Horowitz BJ, Edeelstein SW, Lippman L. Sugar chromatography studies in recurrent candida vulvovaginitis. J Reprod Med. 1984;29:441-3.

41. Kiviat NE, Paavonen JA, Brockway J, et al. Cytologic manifestations of cervical and vaginal infections, I: epithelial and inflammatory cellular changes. JAMA. 1985;253:989-96.

42. Huggins GR, Preti G. Diagnostic clues from vaginal odors. Contemp Ob/Gyn. 1983;22:199-220.

43. Monif GRG. Classification and pathogenesis of vulvovaginal candidiasis. Am J Obstet Gynecol. 1985;152:935-9.

44. Jovanovich R, Congema E, Nguyen HT. Antifungal agents vs. bo- 
ric acid for treating chronic mycotic vulvovaginitis. J Reprod Med. 1991;36:593-7.

45. Van Heusden AM, Merkus HWM, Corbeij RS, et al. Single-dose oral fluconazole versus single-dose topical miconazole for the treatment of acute vulvo-vaginal candidosis. Acta Obstet Gynecol Scand. 1990;69:417-22.

46. Anderson GM, Barrat F. Bergan T, et al. A comparison of singledose oral fluconazole with 3-day intravaginal clotrimazole in the treatment of vaginal candidiosis. Br J Obstet Gynaecol. 1989; 96:226-32.

47. Clark C, Cooper CL, Gorden SF, et al. A multicenter comparison of one-dose tioconazole ointment with three dose terconazole cream in vulvovaginal candidiasis. J Wom Health. 1993;2:189-96.

48. Van Slyke KK, Michel VP, Rein MF. Treatment of vulvovaginal candidiasis with boric acid powder. Am J Obstet Gynecol. $1981 ; 141: 145-8$.

49. Elvik SL. Vaginal discharge in the prepubertal girl. J Pediatr Health Care. 1990;4:181-5.

50. Hilton $\mathrm{E}$, Isenberg $\mathrm{HD}$, Alperstein $\mathrm{P}$, et al. Ingestion of yogurt containing Lactobacillus acidophilus as prophylaxis for candidal vaginitis. Ann Intern Med. 1992;116:353-7.

51. Drutz DJ. Lactobacillus prophylaxis for candida vaginitis. Ann Intern Med. 1992;116:419-20.

52. Rigg D, Miller MM, Metzger WJ. Recurrent allergic vulvovaginitis: treatment with Candida albicans allergen immunotherapy. Am J Obstet Gynecol. 1990;162:332-6.

53. Sobel JD. Recurrent vulvovaginal candidiasis. A prospective study of the efficacy of maintenance ketoconazole therapy. N Engl J Med. 1986;315:1455-8.

54. Eschenbach DA. Bacterial vaginosis: emphasis on upper genital tract complications. Obstet Gynecol Clin North Am. 1989;16: 593-610.

55. Sobel J. Bacterial vaginosis: therapeutic dilemmas. Infect in Med. 1990;5:24-30.

56. Klebanoff SJ, Hillier SL, Eschenbach DA, et al. Control of the microbial flora of the vagina by $\mathrm{H}_{2} \mathrm{O}_{2}$-generating lactobacilli. J Infect Dis. 1991;164:94-100.

57. Krohn MA, Hillier SL, Eschenbach DA. Comparison of methods for diagnosing bacterial vaginosis among pregnant women. J Clin Microbiol. 1992;27:1266-71.

58. Bump RC, Zuspan FP, Besching WJ, et al. The prevalence, sixmonth persistence, and predictive values of laboratory indicators of bacterial vaginosis (nonspecific vaginitis) in asymptomatic women. Am J Obstet Gynecol. 1984;150:918-24.

59. Amsel R, Totten PA, Spiegel CA, et al. Nonspecific vaginitis: diagnostic criteria and microbial and epidemiological associations. Am J Med. 1983;74:14-22.

60. Goldacre MJ, Watt B, Loudon N, et al. Vaginal microbial flora in normal young women. BMJ. 1979;1:1450-3.

61. Haukkamaa M, Stranden P, Jousimses-Somer H, et al. Bacterial flora of the cervix in women using different methods of contraception. Am J Obstet Gynecol. 1986;154:520-4.

62. Hill LH, Ruperalia H, Embil JA. Nonspecific vaginitis and other genital infections in three clinic populations. Sex Transm Dis. 1983;10:114-8.

63. Spiegel CA, Amsel R, Eschenbach D, et al. Anaerobic bacteria in nonspecific vaginitis. N Engl J Med. 1980;303:601-7.

64. Bell TA, Farrow JA, Stamm WE, et al. Sexually transmitted diseases in females in a juvenile detention center. Sex Transm Dis. 1985; 12:140-4.

65. Bump RC, Buesching WJ. Bacterial vaginosis in virginal and sexually active females: evidence against exclusive sexual transmission. Am J Obstet Gynecol. 1988;158:935-9.

66. Thomason JL, Gelbert SM, Wilcoski LM, et al. Proline aminopeptidase activity as a rapid diagnostic test to confirm bacterial vaginosis. Obstet Gynecol. 1988;71:607-11.

67. Meis P, Goldenberg R, Iams J, et al. Vaginal infections and spontaneous preterm birth. Am J Obstet Gynecol. 1995; 172:410. Abstract.
68. Stevens-Simon C, Jamison J, McGregor JA, Douglas JM. Racial variation in vaginal $\mathrm{pH}$ amoung healthy sexually active adolescents. Sex Transm Dis. 1994;21:168-72.

69. Eltabbakh GH, Eltabbakh GD, Broekhuizen FF, et al. Value of wet mount and cervical cultures at the time of cervical cytology in asymptomatic women. Obstet Gynecol. 1995;85:499-503.

70. Byrne MA, Turner MJ, Griffiths M, et al. Evidence that patients presenting with dyskaryotic cervical smears should be screened for genital-tract infections other than human papillomavirus infection. Eur J Obstet Gynecol Reprod Biol. 1991;41:129-33.

71. Paavonen J, Teisala K, Heinonen PK, et al. Microbiological and histopathological findings in acute pelvic inflammatory disease. Br J Obstet Gynaecol. 1987;94:454-60.

72. Soper DE, Brockwell MJ, Dalton HP, et al. Observations concerning the microbial etiology of acute salpingitis. Am J Obstet Gynecol. 1994;170:1008-17.

73. Faro S, Martens M, Maccato M, et al. Vaginal flora and pelvic inflammatory disease. Am J Obstet Gynecol. 1993;169(2S):470-4.

74. Korn AP, Bolan G, Padian N, Ohm-Smith M, Schachter J, Landers DV. Plasma cell endometritis in women with symptomatic bacterial vaginosis. Obstet Gynecol. 1995;85:387-90.

75. Gravett MG, Hammel D, Eschenbach DA, et al. Preterm labor associated with subclinical amniotic fluid infection with bacterial vaginosis. Obstet Gynecol. 1986;67:229-37.

76. Martius J, Krohn MA, Hillier SL, et al. Relationships of vaginal Lactobacillus species, cervical chlamydia trachomatis, and bacterial vaginosis to preterm birth. Obstet Gynecol. 1988;76:89-95.

77. Kurki T, Sivonen A, Renkonen OV, et al. Bacterial vaginosis in early pregnancy and pregnancy outcome. Obstet Gynecol. 1992; 80:173-7.

78. Chen KCS, Forsyth PS, Buchanan TM, et al. Amine content of vaginal fluid from untreated and treated patients with nonspecific vaginitis. J Clin Invest. 1979;63:828-35.

79. McGregor JA, Lawellin D, Franco-Buff A, et al. Protease production by microorganisms associated with reproductive tract infection. Am J Obstet Gynecol. 1986;154:109-14.

80. Morales WJ, Schorr S, Albritton J. Effect of metronidazole in patients with preterm birth in preceding pregnancy and bacterial vaginosis: a placebo-controlled, double-blind study. Am J Obstet Gynecol. 1994;171(2):345-7.

81. Eschenbach DA, Nugent RP, Rao AV, et al. A randomized placebo-controlled trial of erythromycin for the treatment of ureaplasma urealyticum to prevent premature delivery. Am J Obstet Gynecol. 1991;164:734-42.

82. Gravett MG, Nelson P, DeRouenn T, et al. Independent associations of bacterial vaginosis and chlamydia trachomatis infection with adverse pregnancy outcome. JAMA. 1986;256:1899-1903.

83. Minkoff $H$, Grunebaum AN, Schwarz RH, et al. Risk factors for prematurity and premature rupture of membranes: a prospective study of vaginal flora in pregnancy. Am J Obstet Gynecol. 1984; 150:965-72.

84. Hillier SL, Nugent RP, Eschenbach DA, et al. Association between bacterial vaginosis and preterm delivery of a low-birthweight infant. N Engl J Med. 1995;333:1737-42.

85. Hauth JC, Goldenberg RL, Andrews WW, et al. Reduced incidence of preterm delivery with metronidazole and erythromycin in women with bacterial vaginosis. N Engl J Med. 1995;333: 1732-6.

86. Petersen EE, Pelz K. Anaerobic vaginosis. Lancet. 1984;1:337-8.

87. Rosene K, Eschenbach DA, Tompkins LS, et al. Polymicrobial early postpartum endometritis with facultatively anaerobic and anaerobic bacteria, genital mycoplasmas, and Chlamydia trachomatis: treatment with piperacillin or cefoxitin. J Infect Dis. 1986; 153:1028-37.

88. Spiegel CA, Amsel R, Holmes KK. Diagnosis of bacterial vaginosis by direct gram stain of vaginal fluid. J Clin Microbiol. 1983;18:170-7.

89. Pheifer TA, Forsyth PS, Durfee MA, et al. Nonspecific vaginitis. Role of Haemophilus vaginalis and treatment with metronidazole. N Engl J Med. 1978;298:1429-34. 
90. Hill GB, Livengood $\mathrm{CH}$. Bacterial vaginosis-associated microflora and effects of topical intravaginal clindamycin. Am J Obstet Gynecol. 1994;171:1198-204.

91. Jerve F, Berdal TB, Bohman P, et al. Metronidazole in the treatment of nonspecific vaginitis (NSV). Br J Vener Dis. 1984;60: 171-4.

92. Livengood GH, Thomason JL, Hill GB. Bacterial vaginosis: treatment with topical intravaginal clindamycin phosphate. Obstet Gynecol. 1990;76:118-23.

93. Hillier S, Krohn MA, Walls H, et al. Microbiological efficacy of intravaginal clindamycin cream for the treatment of bacterial vaginosis. Obstet Gynececol. 1990;76:407-13.

94. Moi H, Erkkola R, Jerve F, et al. Should male consorts of women with bacterial vaginosis be treated? Genitourin Med. 1989;65: 263-8.

95. Vejtorp M, Bollerup AC, Vejtorp L, et al. Bacterial vaginosis: a double-blind randomized trial of the effect of treatment of the sexual partner. Br J Obstet Gynaecol. 1988;95:920-6.

96. Sexually transmitted disease treatment guidelines, CDC. MMWR. 1997;46:72-3.

97. Burtin P, Taddio A, Ariburnu O, et al. Safety of meronidazole in pregnancy: a meta-analysis. Am J Obstet Gynecol. 1995;172: 525-9.

98. Lossick JG. Treatment of sexually transmitted vaginosis/vaginitis. Rev Infect Dis. 1990;12:S665-81.

99. McGregor JA, French JI, Jones W, et al. Bacterial vaginosis is associated with prematurity and vaginal fluid mucinase and sialidase: results of a controlled trial of topical clindamycin cream. Am J Obstet Gynecol. 1994;171:1048-60.

100. Cotch MF, Pastorek JG, Nugent RP, et al. For the Vaginal Infections and Prematurity Study Group. Demographic and behavioral predictors of Trichomonas vaginalis infection among pregnant women. Obstet Gynecol. 1991;78:1087-92.

101. Dunkelberg WE, Skaggs R, Kellog DS, et al. Relative incidence of Corneybacterium vaginale, Nesserria gonorrhea, and Trichomonas among women attending a veneral disease clinic. Br J Vener Dis. 1970;46:187-90.

102. James JA, Thomason JL, Gilbert SM, et al. Is trichomonalis often associated with bacterial vaginosis in pregnant adolescents? Am J Obstet Gynecol. 1992;166:859-63.
103. Weston TE, Nichol CS. Natural history of trichomonal infection in males. Br J Vener Dis. 1963;39:251-3.

104. Hammill HA. Trichomonas vaginalis. Obstet Gynecol Clin North Am. 1989; 16:531-40.

105. Alderete JF, Pearlman E. Pathogenic Trichomonas vaginalis cytotoxicity to cell culture monolayers. Br J Vener Dis. 1984;60:99-105.

106. Underhill RA, Peck J. Causes of therapy failure after treatment of T. vaginalis. Br J Clin Pract. 1974;28:134.

107. Keith LG, Berger GS, Edelman DA, et al. On the causation of pelvic inflammatory disease. Am J Obstet Gynecol. 1984;149:215-24.

108. McLaren LC, Davis LE, Healy GR, et al. Isolation of Trichomonas vaginalis from the respiratory tract of infants with respiratory disease. Pediatrics. 1983;71:888-90.

109. Lossick JG, Kent HL. Trichomoniasis: trends in diagnosis and management. Am J Obstet Gynecol. 1991;165:1217-22.

110. Spence M. The clinical and laboratory diagnosis of $T$. vaginalis infection. Sex Transm Dis. 1980;7:188-95.

111. Fouts A, Kraus S. Trichomonas vaginalis: re-evaluation of its clinical presentation and laboratory diagnosis. J Infect Dis. 1980; 141:137-43.

112. Meuller M, Meingassrer JG, Miller W, et al. The metronidazole resistant strains of T. vaginalis. Am Obstet Gynecol. 1980;138: 808-12.

113. Riley DE, Roberts MC, Takayama T, et al. Development of a polymerase chain reaction-based diagnosis of Trichomonas vaginalis. J Clin Microbiol. 1992;30:465-72.

114. Aubaert J, Sesta HJ. Treatment of vaginal trichomonas: single 2 gram compared to 7 day course. J Reprod Med. 1982;27:743-5.

115. Hager WD, Brown ST, Kraus SJ, et al. Metronidazole for vaginal trichomonas. JAMA. 1980;244:1219-23.

116. Woodcock KR. Treatment of $T$. vaginalis with a single oral dose of metronidazole. Br J Vener Dis. 1972;48:65-8.

117. Sexually transmitted disease treatment guidelines, CDC. MMWR. 1993;42:71

118. Livengood $\mathrm{CH}$, Lossick JG. Resolution of resistant vaginal trichomoniasis associated with the use of intravaginal nonoxynol-9. Obstet Gynecol. 1991;78:954-6.

119. Dombrowski MP, Sokol RJ, Brown WJ, et al. Intravenous therapy of metronidazole-resistant Trichomonas vaginalis. Obstet Gynecol. 1987;69:524-5. 